\title{
Survey Shows Support for WA Cares Fund and Program Features
}

New research from AARP shows a majority of Washington voters support the WA Cares Fund and that amount increases for the specific program features. The survey of registered voters age $18+$ explored understanding and support of the WA Cares program.

\section{WA Cares Fund Critically Important}

$51 \%$ of Washingtonians say they support the program and support increases when $51 \%$ more information is provided about the key features of the WA Cares Fund Program:
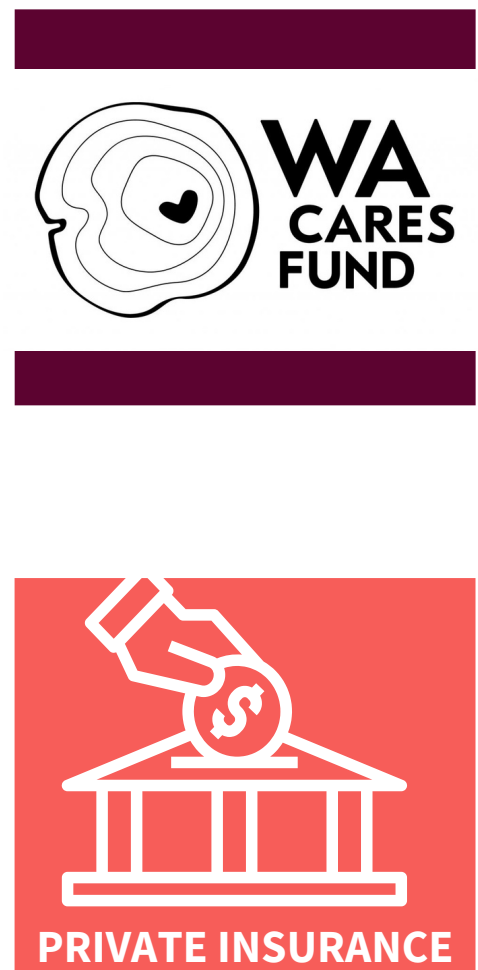

Extremely or very important Somewhat important Not very or not at all important

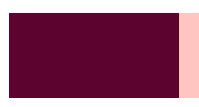

$80 \%$ say it's important that no one can be turned down for pre-existing conditions
Private long-term care insurance often won't insure people with pre-existing conditions or disabilities or will require they pay more.

$76 \%$ say it's important that WA Cares allows participants

Private long-term care insurance rarely allows for direct payments to family caregivers.

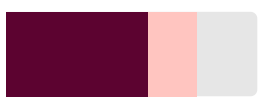

$73 \%$ say it's important that both men and women pay the same amount for coverage

\section{Private long-term care insurance rates for women can be up to $50 \%$ more than for men.}

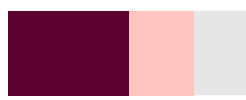

$70 \%$ say it's important that workers only pay into the WA Cares Fund during their working years

Private long-term care insurance payments can continue for decades after retirement

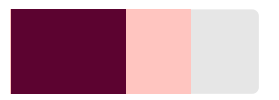

$70 \%$ say it's important that WA Cares costs less than long-term care insurance for most workers

Private long-term care insurance costs the average 60-year-old \$2,057 per year, according to the National Association of Insurance Commissioners. 


\section{Needs of Washingtonians}

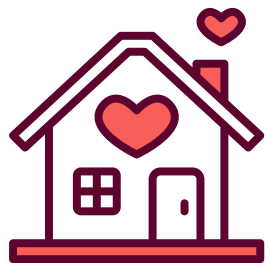

$96 \%$

want services that would allow them or loved ones to stay at home as long as possible

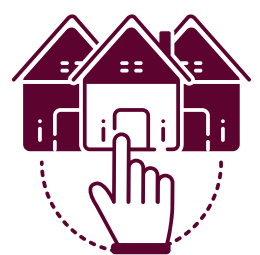

98\%

want to be able to choose where they receive long-term care services

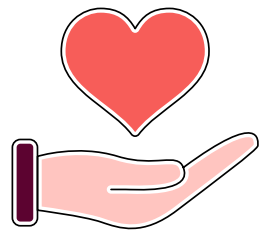

$70 \%$

of Washingtonians 65 and older will require some assistance to live independently as they age*

\section{Who Pays for Long Term Care?}

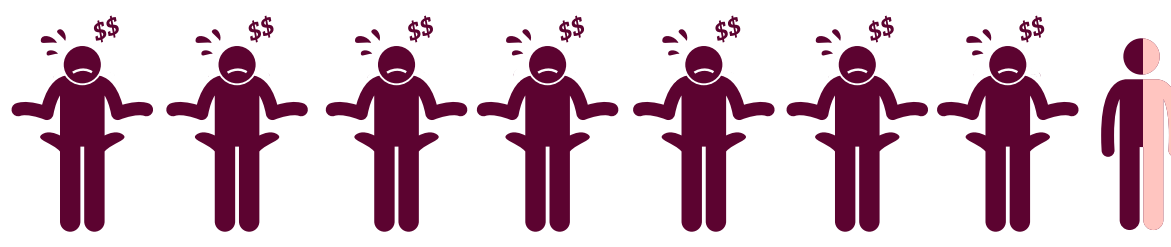

74\% of Washington voters are not confident or only somewhat confident
about their ability to pay for their long-term care needs.

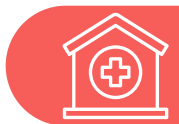

$75 \%$

MISTAKENLY believe private health insurance, Medicare or Medicare supplement insurance would pay for a stay in a nursing home.

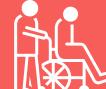

$78 \%$

MISTAKENLY believe private health insurance, Medicare or Medicare supplement insurance would pay for a home visit by a paid caregiver.

\section{Learn More}

Help to inform our communities and ensure all Washingtonians have access to affordable and equitable long-term options care when they need it by sharing your support for the WA Cares Fund!

\section{Visit wacaresfund.wa.gov to learn more. Visit aarp.org/wa to get involved.}

\section{Contacts}

Cathy Maccaul | cmaccaul@aarp.org | AARP Washington Terri Guengerich | tguengerich@aarp.org | AARP Research 